\section{Manus et digitus: uma relação muito delicada*}

\section{Manus et digitus: a very delicate relationship}

\author{
Gizelle Kaminski Corso** $^{* *}$ \\ Instituto Federal de Santa Catarina

\section{Tânia Regina Oliveira Ramos ${ }^{* * *}$ \\ Universidade Federal de Santa Catarina}

Resumo: A proposta deste texto é lançar reflexões sobre a elaboração de materiais na Educação a Distância. Partindo do ensaio de Roland Barthes, "Reflexões a respeito de um manual”, Conferência pronunciada no Colóquio O Ensino da Literatura, em 1969, procuramos verificar em que medida os livros-textos, materiais de suporte/apoio aos alunos da Educação a Distância, revigoram a noção de livro didático, de manual, de guia para os estudos, mediação para o ensino e a aprendizagem das disciplinas de literatura - área em que atuamos nessa modalidade de educação no curso de Letras-Português da Universidade Federal de Santa Catarina. Neste texto também não deixamos de pensar na importância desse material como ferramenta de apoio na formação de professores de Língua Portuguesa e Literatura na Educação Básica.

Palavras-chave: Livros didáticos. Formação de professores de língua e literatura. Educação a distância.

Abstract: The purpose of this paper is to present reflections about the elaboration of materials for students of Distance Education. Departing from the Roland Barthes' essay, "Reflections on a manual”, Conference pronounced in Coloquio the teaching of Literature, in 1969, it is verified in which way the textbooks, support materials/support for students of Distance Education reinvigorate the notion of textbook, a manual, a guide to the studies, mediation for teaching and learning the disciplines of literature - an area in which we operate in this mode of education in Letras-Português course, at Universidade Federal de Santa Catarina. In this text it is still considered the importance of this material as a support for graduating students, future basic teachers of Portuguese.

Keywords: Textbooks. Training of Portuguese and Literature teachers. Distance education.

\section{Inquietações iniciais}

Este texto é motivado diretamente pela paradoxal experiência: escrevemos em coautoria dois "livros-textos" para o Curso de Letras Português, modalidade a distância: um sobre literatura e ensino, e o segundo sobre as relações que a literatura estabelece com as outras linguagens, depois de vivenciar algumas experiências nessa modalidade de ensino,
* Este texto foi apresentado no $\mathrm{X}$ CELSUL - Círculo de Estudos Linguísticos do Sul, em 2012, no GT "Linguagem, Identidade e Subjetividade", coordenado pelas professoras Letícia Fraga (UEPG) e Siumara Aparecida de Lima (UTFPR).

Doutora em Literatura pela Universidade Federal de Santa Catarina, Professora do Instituto Federal de Educação, Ciência e Tecnologia de Santa Catarina. E-mail: <gikacorso@gmail. com>

Doutora em Letras (PUCRio), Professora da Universidade Federal de Santa Catarina. E-mail: <taniaramos@floripa. com.br $>$ 
ou seja, ministrar para o mesmo curso a disciplina Literatura Brasileira III - Literatura Contemporânea, e preparar um material de História da Literatura Brasileira para ser adaptado às especificidades do Curso de Libras. O futuro nos remeteu ao passado, pois tivemos de pensar sobre todas as questões que podem existir quando da elaboração de um livro que tem propósitos científicos e didáticos para acadêmicos provenientes de diversas partes do Brasil e com perfis etários, econômicos, culturais naturalmente diversificados.

Embora nomeados "livros-textos", por atuarem como livro, como possibilidade de leitura, mas muito mais como um material de apoio aos alunos, presença-ausência do professor, do tutor, esses livros vêm desempenhando um importante papel didático nos cursos da Educação a Distância (doravante mencionada como EaD ) da UFSC, sendo encarados como livros didáticos, no sentido de que alguns alunos se valem desse material para os estudos; alguns deles, inclusive, os transformam em exclusiva fonte de pesquisa e de leitura de determinada disciplina.

Para trazer à tona essas reflexões, dividimos este texto em três partes: na primeira apresentaremos reflexões mais pontuais sobre os manuais, os livros didáticos, para, em seguida, esclarecermos e vislumbrarmos sua presença marcante no contexto da EaD da UFSC. Na terceira e última parte, trazemos para a discussão a transposição desses livros-textos no ensino presencial e sua relação com os alunos dessa modalidade de ensino.

\section{Manuais, mãos nos ais}

O título desse tópico na sua ludicidade formal é a síntese da primeira reflexão. A educação a distância - EaD - não é nova, tampouco surgiu com as tecnologias da informação e comunicação, mas é fruto do ensino por correspondência iniciado no século XIX (MOORE; KEARSLEY, 2010). Portanto, já logra mais de um século de existência e de experiências vivenciadas. Sobre a ideia básica de EaD , afirmam esses autores,

A ideia básica de educação a distância é muito simples: alunos e professores estão em locais diferentes durante todo ou grande parte do tempo em que aprendem e ensinam. Estando em locais distintos, eles dependem de algum tipo de tecnologia para transmitir informações e lhes proporcionar um meio para interagir. (MOORE; KEARSLEY, 2010, p. 1).

A EaD pressupõe aprendizado planejado e variado, autonomia, criação e criatividade. Ao longo de sua história acumula, segundo Moore e Kearsley, uma escala evolutiva de cinco gerações:

- Primeira Geração - meio de comunicação era o texto; a instrução por correspondência; 
- Segunda Geração - ensino por meio da difusão pelo rádio e pela televisão;

- Terceira Geração - não é muito caracterizada pela tecnologia de comunicação, mas, preferencialmente, pela invenção de uma nova modalidade de organização da educação, de modo mais notável nas universidades abertas;

- Quarta Geração - Teleconferência;

- Quinta Geração - Internet/Web.

Nosso ingresso na modalidade de atuação EaD , portanto, permite nos enquadrar na Quinta Geração. Por ser recente, ainda nos causa surpresas, permite-nos expectativas, gera estranhamentos. Estamos nos habituando a um novo moodle de ser, de entender, de olhar para um ensino e uma aprendizagem que se fazem sem a presença corpórea, física, do professor. Em nosso envolvimento com a EaD, além de nos situarmos em um terreno arenoso, porque até então desconhecido, nos encontramos em uma situação de retorno ao passado: pela elaboração dos materiais de suporte e apoio, os famosos livros-textos, retornamos à ideia de manuais, um dos primeiros formatos do que posteriormente foram chamados de livros didáticos.

Se fizermos um percurso histórico da relação que existiu entre a produção de conhecimento e o ensino, veremos que, na Antiguidade, e até aproximadamente o século XV, o mestre, o professor, se identificava por ser um produtor de conhecimentos, e um divulgador de seu saber específico. Gramáticos, por exemplo, ensinavam a gramática; retóricos, a retórica, ou seja, não havia separação entre aquele que produzia e aquele que ensinava, pois isso competia ao detentor do conhecimento: ele sabe, ele pode ensinar. Essa situação foi alterada mais tarde, no período em que parece haver, conforme apresenta Geraldi (2010) em sua releitura dessas relações históricas, a primeira grande divisão social do trabalho educativo: o Mercantilismo, em que a figura do mestre passou a ser a de um transmissor de um saber alheio - situação que permanece até hoje, na maioria dos casos, no contexto educacional. O saber é comprado, o saber é vendido, o saber é comercializado, o saber é compartilhado.

Voltemos agora ao nosso ponto de partida. Nos “moldes” em que é elaborada e pensada na UFSC, e na maioria das universidades que aderiram à UAB - Universidade Aberta do Brasil, a Educação a Distância faz com que vivenciemos as duas situações apresentadas acima: elaboramos tópicos de um livro-texto baseadas na ementa da disciplina, escolhemos referências, aspectos teóricos a serem aprofundados, relemos autores, livros, teorias, escrevemos, reescrevemos, somos lidas e avaliadas, produzimos conhecimento a partir da pesquisa e de nossas formações doutorais, passamos por uma leitura editorial que opina, discute, diverge, auxilia, comenta, dialogamos com um Designer Institucional com formação na área, na maioria das vezes, para sermos posteriormente publicadas e enviadas em forma de livros-textos aos polos. 
Ou seja, produzimos e disseminamos o próprio "saber” (no sentido de que apresentamos nossas reflexões teóricas, nosso ponto de vista; trazemos nossa voz no livro-texto, fazemos as nossas escolhas, produzimos uma "fala”, para um livro que se vale da necessidade de substituir uma ausência - a do professor, a do tutor). Melhor dizendo, produzimos um livro, um material que será o "livro de cabeceira" da disciplina, o "carro-chefe”, o "Virgílio-cicerônico"1 - e assim os denominamos porque vimos que muitos alunos os compreendem desta forma: um suporte, um amparo, um apoio. Alguns, no entanto, veem nesses livros, como já mencionamos, a única leitura para a disciplina, a única fonte de pesquisa e de busca, entendendo que ler "o material da disciplina” restringe-se à leitura exclusiva do livro-texto, pois ali está a verdade do professor. Mesmo se submetendo as orientações do Ambiente Virtual de Aprendizagem - AVEA - muitas vezes desconsideram as sugestões de leitura contidas na Webteca (biblioteca digital de cada disciplina, que é ampliada e alimentada no transcorrer da disciplina e no decorrer do curso). Aos poucos vamos conseguindo modificar esse modo de se relacionar com as práticas de leitura já enraizadas pelas suas próprias formações básicas e médias.

O processo de escrever um livro texto requer disciplina (disciplina para a disciplina). Os livros-textos são produzidos com antecipação, mas são elaborados como mais uma das atividades de rotina acadêmica em que estão obrigatoriamente envolvidos os professores. Como eles passam por vários processos (leitura da Comissão Editorial, revisão, Designer Institucional, capista, imprensa ou editora) muitas vezes são publicados às vésperas ou pouco tempo antes do início do bimestre, trimestre ou semestre (conforme a estruturação da disciplina).

O curso de Letras-Português, da UFSC, já está em sua segunda edição, com Polos apenas no Estado de Santa Catarina, nas cidades de: Blumenau, Canoinhas, Chapecó, Itajaí, Pouso Redondo, Treze Tílias e Videira, e cujo ingresso ocorreu no início de 2011. Livros-textos elaborados para a primeira edição do curso² são/estão sendo “reaproveitados”, numa otimização necessária intelectual e economicamente. Em uma disciplina anterior que ministramos na reedição do curso, apropriamo-nos de material produzido por outro professor, ou seja, embasamos a disciplina pela voz-alheia, utilizando o livro-texto elaborado por um professor que a ministrou pela primeira vez. Quando falamos a vis, queremos registrar como a oralidade, a dicção, as marcas autorais estão bastante presente no material para EaD. Tivemos dificuldade? Sim, naturais, mas não inviáveis.

Trilhadas pelo caminho do outro no que se refere ao texto impresso, inserimos nossa voz, nossa marca pessoal, na elaboração do Ambiente (a página de acesso à disciplina) e nas atividades do curso. Escrevemos igualmente um capítulo ausente na primeira edição. Demos a ele um formato de e-book. Essa retomada de material previamente produzido, de
${ }^{1}$ Virgílio (70 a.C. - 19 a.C.), poeta latino, conhecido pela publicação da epopeia Eneida. Na Divina Commedia, do poeta italiano Dante Alighieri, Virgílio é escolhido para ser o seu guia na peregrinação pelo reino do Inferno até a entrada no Purgatório. "Cicerone" é um termo antigo para definir um guia de turismo. A expressão "Virgílios cicerônicos" foi utilizada por Monteiro Lobato, em carta a Godofredo Rangel, em 1906, na qual dizia, a respeito de adaptações e da leitura de clássicos: “Quanto aos épicos antigos, Dante, Milton, Homero, só com bons intérpretes, com Virgilios ciceronicos. O próprio Lusiadas nunca li inteiro. Cansa-me. Já investi contra o bloco cinco vezes. Começo achando-o belíssimo, e vai belíssimo até dez ou dozes estrofes; daí por diante entram a amiudar-se os bocejos e a admiração vai morrendo". (LOBATO, 1972, p. 69).

${ }^{2}$ A primeira edição do curso contou com Polos em três estados brasileiros: Minas Gerais (Divinolândia de Minas), Paraná (Cruzeiro do Oeste e Pato Branco) e Santa Catarina (Treze Tílias e Videira). O ingresso dessa primeira turma aconteceu no ano de 2008. 
percursos já traçados, nos leva a pensar que esses livros-textos também se transforma(ra)m em uma herança acadêmica; estão instaurando um legado e, portanto, constituindo-se em acervo bastante peculiar. A marca própria de cada docente impressa (leia-se também “em pressa”, por conta dos prazos) fica no Acervo da CAPES e nas instituições como produção de professores voltados para o ensino de graduação. Essas marcas podem ser já anunciadas nas próprias introduções dos livros, onde a assinatura e o tom já nos apresenta. Optamos por ilustrar dois momentos de nossos livros-textos.

Escolhemos, como primeiro exemplo, a “Apresentação” do livro-texto mais recente que escrevemos, Estudos Literários IV, publicado em 2011, última disciplina de literatura do currículo do curso de Letras-Português da UFSC. Essa disciplina procura estabelecer um diálogo da literatura com as outras linguagens (cinema, teatro, artes plásticas, música, por exemplo). Selecionamos a Apresentação deste livro porque feito com a colaboração de outros leitores críticos, doutores, doutorandos e mestres em literatura pela mesma instituição. Com isso, queremos demonstrar a multiplicidade autoral, instaurada não apenas pela presença da figura do Designer Instrucional, mas pela possibilidade de troca e diálogo com leitores mais experientes em determinadas áreas com o intuito de enriquecer o material e, consequentemente, colaborar para a formação dos nossos professores de Língua Portuguesa:

\section{Apresentação}

Esse é o último livro-texto de Estudos Literários de nosso Curso de Letras. Um livro que procurará mostrar o diálogo da literatura com outras linguagens. Um livro para o qual fizemos escolhas e procuramos dialogar com outros leitores dessas tantas linguagens: Ana Maria Alves de Souza, formada em Artes Plásticas; Daniel Soares Duarte, formado em Letras e músico; Jade Gandra Dutra Martins, jornalista e especialista no teatro de Nelson Rodrigues; e Vanessa Dutra Martins, historiadora e especialista na linguagem das correspondências. Ana Maria é Mestra em Antropologia e Literatura; Daniel é Mestre e Doutorando em Literatura; Jade e Vanessa, Doutoras em Literatura. Fizemos questão que cada um deles contribuísse com o nosso conhecimento e o conhecimento de vocês. Gente que faz.

Qual o objetivo dessa disciplina? Projetar a futura prática como docentes, como profissionais e como leitores para essas outras linguagens. Formados em Letras, professores, deverão estar abertos para essas novas linguagens. Na medida em que nossos olhos se voltam para o século XXI, é preciso que os estudos literários se voltem para a estética das novas tecnologias, para a música, para o cinema, para as artes plásticas, para o teatro, para a memória, para a oralidade. Se a estética tem um papel tão dominante no pensamento moderno, isto resulta, em parte, da versatilidade do conceito. Preferimos aqui ler a ideia mesma do mundo como artefato. 
Na relação estética e modernidade, que norteou o nosso olhar sobre as coisas ditas, o que se revelou mais do que a necessidade de procurar o oculto foi a facilidade de adentrar o simbólico. Lendo deste lugar, verificamos com grata surpresa o quanto os estudos literários, em diálogo com outras linguagens artísticas, tornam-se uma audaciosa tentativa de ler o moderno e a modernidade, ou reler a tradição, para caracterizar produtos culturais de certas formas díspares na sua caracterização estética. Ou não seriam tão diferentes assim? Por que não considerarmos os atos da vida social como obras-de-arte? Literatura, artes plásticas, música, cinema, textos memorialísticos, fotografia, correspondência, dramaturgia, convive(ra)m harmonicamente sem fronteiras e reconhecendo os limites de suas representações.

Para você, leitora, leitor, uma oportunidade de olhar diferente por diferentes olhares. Pretendemos aguçar em você uma percepção mais atenta, sensível, perspicaz, mas não menos crítica, nas relações (in)findáveis que a literatura estabelece com as outras linguagens. E, para que esse percurso ocorra de maneira proveitosa e eficiente, elaboramos nove capítulos que problematizam, discutem, evidenciam algumas dessas relações que aqui denominamos: Poéticas do olhar, Poéticas do gesto, Poéticas dos sentidos, divididas - mas não encerradas, estagnadas - e definidas por aquilo que lhes é primeiramente predominante: o olhar, o gesto, o sentido. Em Encontro final - Literatura e outras linguagens, apresentamos uma leitura de um livro contemporâneo que procura mostrar a possibilidade de usarmos esta poética dos sentidos nos estudos literários. Um número ímpar de possibilidades, de relações, de liames, de emaranhamentos.

Tânia e Gizelle (RAMOS; CORSO, 2011, p. 7-8).

Trazemos, como segundo exemplo daquilo que vimos discutindo neste texto, outra questão que merece ser ilustrada. São "basicamente" perguntas, provocações que procuramos apresentar ao final de cada capítulo dos livros-textos, como uma forma de continuidade, de alimento para discussões posteriores, bem como de retomada do conteúdo lido/estudado precedidas por uma sugestão imperativa: "Reflita(m) e troque(m) ideias com seus colegas, tutores e professores”. Embora algumas delas tenham sido utilizadas como atividades a serem postadas no Ambiente Virtual AVEA, essas perguntas, no geral, não são obrigatórias; suas respostas não devem ser enviadas formalmente ao tutor, mas constituem-se em oportunidades a mais de reflexão; de lançar outro(s) olhar(es) sobre os textos lidos. As questões que se seguem foram retiradas de outro livro-texto que escrevemos, intitulado Literatura e ensino (2010), disciplina que procura lançar reflexões sobre o ensino da literatura na sala de aula.

Reflita(m) e troque(m) ideias com seus colegas, tutores e professores:

1. "Não quero aqui culpar o livro didático pela dominação e dependência cultural e intelectiva dos professores; na verdade, eles apenas representam o estado de pobreza intelectual dos professores e, consequentemente, 
dos alunos de literatura” (LEAHY-DIOS, 2000, p. 206). O que você(s) pensa(m) a respeito dessa afirmação da professora Cyana Leahy-Dios? Seriam os livros didáticos a representação do estado de pobreza intelectual dos professores e dos alunos de literatura?

2. Separação de língua e literatura, uso exclusivo do livro didático, falta de professores leitores e metodologia de ensino sistematizada, seriam esses fatores pertinentes do fracasso do ensino de literatura na escola?

3. Alguns pesquisadores afirmam que muitos livros didáticos limitam-se a cobrar o que não ensinam. Você(s) concorda(m)? Faça(m) uma pesquisa em diferentes livros didáticos, converse(m) com professores, tutores, colegas, e justifique(m) sua(s) resposta(s).

4. Traga(m) para seus polos livros didáticos que usou(usaram) no seu ensino fundamental ou ensino médio ou, se professores estejam usando com seus alunos. Procure(m) pensar sobre a seguinte questão: Embora haja preocupação de algumas editoras e coleções em explorar o texto literário no livro didático, em sua(s) pesquisa(s), você(s) encontrou(encontraram) maior tratamento aos textos literários ou aos não literários? Há uma maior presença de que tipo de texto? (RAMOS; CORSO, 2010, p. 45).

Assim, o que pretendemos demonstrar com esse texto, igualmente autoral, é o nosso olhar-experiência a respeito da elaboração de materiais para a Educação a Distância. Ou seja, precisamos (re)aprender a escrever manuais, a fazer estudos dirigidos, a elaborar provas de múltipla escolha. Trabalhamos com excertos, antologias, críticas e literárias, escrevendo discursiva e cartesianamente nossas aulas de literatura, começo, meio e fim, ilustrando com fragmentos, selecionando o cânone entre os cânones, estabelecendo links a partir de rodapés. Há muito tempo a historiografia e o discurso crítico não haviam sido tão recortados e tão seletivos. Nunca mais tínhamos nos valido das certezas positivistas da historiografia e nunca carecemos tanto da ausência de uma história das visualidades e dos acervos digitais.

Em pleno século XXI nos reportamos, então, às reflexões acerca dos manuais, feitas por Roland Barthes em 1969 (BARTHES, 1988), ao império da eloquência, evocando a retórica disciplinar do século XVIII e XIX estudado por Roberto Acizelo de Souza, para entender essa nossa nova produção acadêmica. Como nos diria Cazuza: "Eu vejo o futuro repetir o passado, eu vejo um museu de grandes novidades”.

Para ilustrar, vamos aos manuais. Roland Barthes, em "Reflexões a respeito de um manual”, diz que a história da literatura é um objeto essencialmente escolar, que só existe por seu ensino. A literatura, por sua vez, é um objeto de ensino feita de monemas: autores, obras, escolas, movimentos, gêneros e séculos. Sobre esses objetos a combinação de traços e predicados, quase sempre em oposição: Romantismo/Classicismo; 
Romantismo/Realismo; Modernismo/Parnasianismo; produzindo individualidades ou certos indivíduos literários. É assim que, nos manuais, os próprios séculos acabam por apresentar-se sempre de maneira paradigmática. Diz diretamente Barthes sobre estas questões: "O que estou dizendo é simplesmente a amostra do que se poderia imaginar como uma espécie de pequena gramática da nossa literatura, gramática que produziria umas espécies de individuações estereotipadas: os autores, os movimentos, as escolas” (BARTHES, 1988).

A gramática de nossa literatura precisa, no entanto, na feitura dos livros didáticos que tanto criticamos, de textos, exemplos, remissões. É neste momento que retomamos a leitura de Luiz Ruffato, escritor contemporâneo, colecionador e organizador de antologias. Antes de analisar a primeira antologia brasileira de contos, excluídas as de fins didáticos, Contos Brasileiros, uma edição de 404 páginas, publicada pela Livraria Garnier do Rio de Janeiro, impressa na Bélgica em 1922, organizada pelos poetas Alberto de Oliveira e Jorge Jobim (poeta bissexto e pai de Antônio Carlos Jobim $)^{3}$, Luiz Ruffato posiciona-se a respeito das antologias afirmando que:

As antologias servem, de maneira geral, para evidenciar e consolidar nomes, e serão tanto mais significativas quanto maior a capacidade de apreensão do "espírito do tempo", demonstrada pelo responsável pela escolha dos autores. Ao fim e ao cabo, trata-se de um esforço para normatizar o gosto literário, baseado em interesses os mais diversos, sejam da sociedade, do mercado editorial ou de grupos marginalizados ou não [...]. Mesmo as seletas geracionais, que prescindem dessa mescla, necessitam, para serem aceitas, de um garantidor que pode ser o autor de prestígio que assina a apresentação do livro, a editora que empresta crédito ao projeto, ou o grupo que sustenta a ação. (RUFFATO, s/d, s/p).

Neste futuro repetindo o passado naquilo que não devemos hoje chamar apenas de livro, mas material impresso, guia de estudo, porque o objeto livro, seu conteúdo, fica a serviço da interação virtual, vemos a combinação do manual pensado por Barthes com uma estética das antologias, dos fragmentos, que buscam operar neste novo perfil de universitários a assimilação das informações, o gosto, o pensamento crítico, motivando e remetendo à leitura das obras como um todo. Uma motivação a distância, ainda que amparados nos polos por uma estrutura física, não mais mediados pelo pensamento imediato e pela presença de um professor da disciplina, cuja voz permanece imperativa nos comandos escritos: Leia. Leia mais!

Não é em vão que os intermediários vão se chamar tutores. A cátedra volta a existir: graduados, mestrandos, mestres, doutorandos e doutores, assistentes, tornam-se tutores, estabelecendo o diálogo virtual e presencial, uma imprescindível participação colaborativa. Na dúvida e na tensão do diálogo como este que estabelecemos agora - porque escrevemos o que pode se chamar de livro didático ou material impresso, a voz da experiência
${ }^{3}$ Estes dados são todos retirados do artigo de Luiz Ruffato. 
provisória e a crítica debatem-se na avaliação do material e nas próprias escolhas. As certezas da historiografia, as assertivas informacionais, a gramática dos estilos, os manuais, as múltiplas escolhas, as antologias, as escolhas de textos, os fragmentos, têm nos permitido alguns acertos provisórios nessa forma de ensino.

Retomamos Roland Barthes quando nos recomenda fazer de nós mesmos o centro dessa história. E nesse ponto entra Bakhtin (2000) e a busca ao diálogo, o dialogismo desejado, a escritura, ao mesmo tempo como subjetividade e comunicabilidade, a existência sempre de um outro nos textos que escrevemos. Porque a despeito dos manuais, dos fragmentos, do gosto literário pelo exemplo, pelo antológico, pela seletiva dos cânones, o livro didático - ou como querem chamar - material impresso, é realmente a materialidade de alguma coisa que a presença nos desobriga. Você lembra o que vimos na Unidade 3? Recupere o início de nossa explicação. Volte à aula anterior. Reveja agora o que vimos sobre a Carta de Pero Vaz de Caminha. Localize agora o poema "Se eu morrer amanhã" do poeta romântico Álvares de Azevedo em <www.literaturabrasileira.ufsc. br> Leia. Leia mais! Gestos automáticos para uns, gestos de interpretação para outros. Buscas, perdas, memória e esquecimento.

Guias para os estudos, guias para os trabalhos, guias para as provas, guias para as aulas, para o todo e sempre, os livros-textos. Um pedaço de Universidade carregada debaixo do braço, dentro da mochila, dentro da bolsa, no banco do carro, na sacola sobre os bancos dos ônibus que os leva para os polos. Espalhados pelos diversos cantos da casa, esses livros, acabam sendo o primeiro contato material-científico que os alunos têm com o professor; são a garantia e a certeza do amparo, do porto-seguro. Nos encontros presenciais, marcam presença, por mais que não sejam diretamente utilizados, simbolizando um compromisso. E se o professor solicitar? Abram o livro na página... Ele há de estar lá.

Nas disciplinas “Estágio Supervisionado I” e “Estágio Supervisionado II”, ocorridas em 2011 e 2012, respectivamente, que correspondem aos estágios obrigatórios dos acadêmicos de Letras-Português da UFSC, em turmas dos ensinos Fundamental e Médio, constatamos que os livros-textos de "Morfologia do Português”, “Literatura Brasileira III”, “Estudos Literários III”, “Literatura Portuguesa I”, entre outros, foram utilizados como material para elaboração dos Projetos [das aulas] dos estagiários. Disseminação evidente, não como transposição didática, em que o conhecimento científico é transposto para a sala de aula - aplicacionismo de conhecimentos científicos -, mas pela elaboração didática (HALTÉ, 2008), colaborando para o domínio das práticas de linguagem de seus alunos. Por escolhas pautadas em critérios bem definidos, em seleção apropriada.

Essa atitude levou esses estagiários a fazerem o percurso inverso do habitual: a migrarem dos livros didáticos adotados pela escola para os 
livros-textos lidos, usados na Universidade, em sua formação. Os livrostextos, ressaltamos, trazem textos completos, como: contos, poemas, crônicas e, portanto, constituem-se em importante repertório para os alunos, futuros professores de Língua Portuguesa.

Buscas da presença na distância, buscas do distanciamento proporcionado pelo presencial. $\mathrm{O}$ que temos visto, com nossa experiência de professoras das modalidades a distância e presencial da UFSC foi uma inversão de certos paradigmas e dos lugares institucionais: recebemos manifestações de alunos do Curso Letras Português presencial que desejavam o uso desses livros em sala de aula.

Por que os alunos da EaD ganham livros e nós, não? Por que se facilita mais para eles? Comparações (des)propositadas, permeadas de um ciúme mal disfarçado, de tentar ver-se no outro porque melhor. Porque com livro-texto a vida acadêmica se torna [aparentemente] mais fácil, mais interessante, pois a trajetória é mais bem elaborada, pensada, articulada. Porque há percursos bem definidos - a possibilidade de vislumbrar o "futuro” da disciplina folheando páginas, percorrendo capítulos, lendo títulos e subtítulos. Possibilidade, também, da leitura antecipada, sem esperas, pelo olhar distante - do início ao fim, pelo arquivamento do amparo teórico na estante, sempre ao alcance das mãos. Pela síntese, pela ideia de Unidade, pela práxis.

Nesta geografia e nos deslocamentos teóricos, a síntese da nossa experiência desejou trazer à tona questões contemporâneas das necessidades pragmáticas que estabelecemos com os arquivos da memória e com a história da literatura. Ou das literaturas. Há processos contínuos de mudança na relação que se estabelece entre o conhecimento acumulado e uma prática que precisa ser renovada, mas que se submete àquele suporte que tem se mostrado como o mais poderoso auxiliar para os estudos de literatura: o livro, o impresso, a sistematização historiográfica, os textos, mesmo que sujeitos a novos formatos.

A despeito de pressentirmos "um museu de grandes novidades", muito mais integradas do que apocalípticas, rendemo-nos ao mais frágil dos instrumentos de apoio, porque no momento em que escrevemos, tudo o que aqui representamos - na provisoriedade de nossa experiência - já atingiu o estatuto universitário de grandes projetos disseminatórios: o ensino a distância e do quanto ele se vale do modelo do livro didático para a concretização do processo ensino e aprendizagem.

O material que produzimos na UFSC para outros ou para o Outro, cuja depositária é a CAPES ${ }^{4}$ - manuais, guias, antologias - exercício de escrita por tantos anos desaprendido, quer resultar no pacto entre o lembrar e o esquecer sem comprometer os atos de ver na gramática e na tradição de nossa literatura a mesma história tantas vezes lida: autores, obras e textos.
${ }^{4}$ Art. 25. À Diretoria de Educação a Distância compete: I - fomentar as instituições públicas de ensino superior e polos municipais de apoio presencial, visando a oferta de qualidade de cursos de licenciatura na modalidade a distância; II - articular as instituições públicas de ensino superior aos polos municipais de apoio presencial, no âmbito da Universidade Aberta do Brasil UAB; III - subsidiar a formulação de políticas de formação inicial e continuada de professores, potencializando o uso da metodologia da educação a distância, especialmente no âmbito da UAB; IV - apoiar a formação inicial e continuada de profissionais da educação básica, mediante concessão de bolsas e auxílios para docentes e tutores nas instituições públicas de ensino superior e tutores presenciais e coordenadores nos polos municipais de apoio presencial; e V - planejar, coordenar e avaliar, no âmbito das ações de fomento, a oferta de cursos superiores na modalidade a distância pelas instituições públicas e a infraestrutura física e de pessoal dos polos municipais de apoio presencial, em apoio à formação inicial e continuada de professores para a educação básica. 


\section{Livros-textos que substituem uma fal(t)a}

O que quisemos demonstrar a partir desta leitura, que escrevemos atando a ponta de nossas duas vidas em diferentes etapas de formação e de atuação, é que o livro, aliado às novas tecnologias, não mais se ressentirá da falta de um diálogo com o pictórico, com o fílmico, com o imagético, com o sonoro, com a literatura em meio eletrônico, esses campos instáveis que ao lado da palavra escrita são produtores de sentidos. Se neste texto pensamos nos livros didáticos, de Comunicação e Expressão, Linguagens, Português, Literatura, Língua Portuguesa, dialogando abertamente com o ensino a distância, o fizemos porque nessa modalidade de ensino eles não mais apenas surgem como suporte a professores, tutores e alunos, mas substituem uma fal(t)a, tornam-se presença e ausência, fragmentos e retalhos, mosaicos para múltiplas leituras e tessituras.

O sistema literário deve se somar ao sistema figurativo de uma memória cultural e de novas tecnologias para que não mais precisemos reconhecer ou ter que discutir a fragilidade do livro didático ou livro-texto. Eles devem sempre servir de suporte de aproximação dos alunos com a sistematização dos conteúdos de qualquer nível de ensino, seja pela ilustração (no sentido de conhecimento e de visualidade), seja pela síntese, seja por um modo de interação cooperativa entre aquele que ensina e aquele que apre(e)nde conteúdos.

O importante é que a resposta à pergunta de Roland Barthes em reflexões a respeito de manuais de literatura - o que fica da literatura depois do colégio? - seja dada pelas lembranças e esquecimentos dos professores e dos alunos da Universidade Aberta do Brasil, ou mesmo dos alunos presenciais, que se familiarizam cada vez mais com o moodle - ou o jeito moodle de ser. O impresso, o livro, manus e digitus, em Letras se complementam, mas temos certeza de que a interação dele com as novas tecnologias não permitirá que se repita a amarga reflexão de Graciliano Ramos em seu romance Infância a respeito da materialidade de seu manual escolar: "Um grosso volume escuro, cartonagem severa. Nas folhas delgadas, incontáveis, as letras fervilhavam, miúdas, e as ilustrações avultavam num papel brilhante como rasto de lesma ou catarro seco” (2003, p. 12).

\section{Referências}

BAKHTIN, M. Estética da criação verbal. 3. ed. São Paulo: Martins Fontes, 2000.

BARTHES, R. A morte do autor. In: O rumor da língua. São Paulo: Editora Brasiliense, 1988, p. 65-70.

Reflexões a respeito de um manual. In: O rumor da língua. São Paulo: Editora Brasiliense, 1988, p. 35-59. 
CANCLINI, Néstor García. Leitores, espectadores e internautas. Tradução de Ana Goldberger. São Paulo: Iluminuras, 2008.

CANDIDO, Antonio. O direito à literatura. In: Vários escritos. 3.ed. rev. e ampl. São Paulo: Duas Cidades, 1995, p. 235-263.

CEIA, C. A literatura ensina-se? Estudos de Teoria Literária. Edições Colibri: Faculdade de Letras de Lisboa, Portugal, 2004.

COMPAGNON, Antoine. O demônio da teoria: literatura e senso comum. Tradução de Cleonice Paes Barreto Mourão e Consuelo Fortes Santiago. Belo Horizonte: UFMG, 2001.

GERALDI, J. W. A aula como acontecimento. São Carlos: Pedro e João Editores, 2010.

HALTÉ, J. F. O espaço didático e a transposição. Fórum Lingüístico, Florianópolis, p. 117-139, jul./dez. 2008.

LOBATO, M. A barca de Gleyre. 14. ed. São Paulo: Editora Brasiliense, 1972. [Obras completas de Monteiro Lobato - vol. 8].

MOORE, M.; KEARSLEY, G. Educação a Distância: uma visão integrada. Tradução de Roberto Galman. São Paulo: Cengage Learning, 2010.

RAMOS, G. Infância. Rio de Janeiro: Record, 2003.

RAMOS, T.; CORSO, G. Literatura e ensino: $5^{\circ}$ período. Florianópolis, SC: UFSC, 2010.

. Estudos literários IV: 8 período. Florianópolis, SC: UFSC, 2011.

RUFFATO, Luiz. Antologias. Disponível em: <http://vitaletteraria. blogspot.com.br/2009/06/antologias.html>. Acesso em: 12 ago. 2011.

VAL, M. C. (Org.). Alfabetização e língua portuguesa: livros didáticos e práticas pedagógicas. Belo Horizonte: Autêntica Editora, Ceale/FaE/ UFMG, 2009. (Coleção Linguagem e Educação)

VILELA. M. G. Sobre o ensino da literatura: os ensinamentos de Xerazade. In: G. RIO-TORTO, G.; FIGUEIREDO, O.; SILVA, F. (Coord.). Estudos em homenagem ao Professor Doutor Mário Vilela (v. 2, p. 633-641). Porto: Faculdade de Letras da Universidade do Porto, 2005. Disponível em: <http://ler.letras.up.pt/uploads/fi cheiros/4593.pdf>. Acesso em: 13 jul. 2010.

Recebido em: 27/02/2013

Aprovado em: 06/07/2013 